\title{
Urinary $\mathrm{N}$-acetyl- $\beta$-D-glucosominidase in rheumatoid arthritis
}

\author{
M. Perwaiz Iqbal, ${ }^{1,3}$ Azra A. Ali, ${ }^{2}$ \\ M. Anwar Waqar ${ }^{1}$ and N. Mehboobali ${ }^{1}$ \\ 1 Departments of Biochemistry and Medicine, \\ The Aga Khan University, Karachi 74800, Pakistan \\ 2 Department of Medicine, The Aga Khan University, Karachi 74800, Pakistan \\ 3 Corresponding author \\ Accepted 28 July 1998
}

Abbreviations: NAG, N-acetyl $\beta$-D-glucosaminidase; RA, rheumatoid arthritis; NSAID, non-steroidal antiinflammatory drug

\begin{abstract}
Excretion of urinary $N$-acetyl $\beta$-D-glucosaminidase (NAG) and its isoenzyme patterns were studied in two groups of patients with rheumatoid arthritis (RA) and in normal control subjects. Urine samples were collected from 30 seropositive RA patients, 19 seronegative RA patients, and 15 normal healthy subjects. All the patients and normal subjects were assessed to have normal liver and kidney functions. A small portion of the urine sample was dialyzed against $0.01 \mathrm{M}$ phosphate buffer, pH 7.0 and NAG activity was monitored. Mean \pm SD values of urinary NAG in seropositive RA patients, in seronegative RA patients and in normal healthy subjects were found to be $4.20 \pm 3.73 \mathrm{U} / \mathrm{g}$ creatinine, $2.96 \pm 2.11$ $\mathrm{U} / \mathrm{gm}$ creatinine, and $1.71 \pm 0.6 \mathrm{U} / \mathrm{g}$ creatinine, respectively. The mean urinary NAG value in RA patients was found to be significantly higher $(P<$ 0.05) in seropositive RA compared to the mean NAG value in normal healthy subjects and patients with seronegative RA when analyzed by one way ANOVA and Tukey-HSD test. The mean proportion of isoenzyme form $B$ to isoenzyme form $A$ in seropositive RA patients was also found to be significantly different $(P<0.05)$ from the mean proportion of these forms in normal healthy subjects and seronegative RA patients. There also appears to be a correlation between the concentration of urinary NAG and severity of the disease in seropositive RA.
\end{abstract}

Key Words: $N$-acetyl- $\beta$-D-glucosaminidase, rheumatoid arthritis, seropositive, seronegative, isoenzymes

\section{Introduction}

$N$-Acetyl $\beta$-D-glucosominidase (NAG) is a lysosomal enzyme, which is mainly present in proximal convoluted tubules. Its levels in urine have been shown to be elevated in a number of diseases, such as diabetes mellitus (Whiting et al., 1979a; 1979b; Hanseus et al., 1983; Shimajo et al., 1987; Skrha et al., 1987; Severni et al., 1988; Watts et al., 1988), renal stone disease (Javed et al., 1992) and impaired renal function disorders (Ellis et al., 1975). More recently, it has been reported that urinary NAG levels are elevated in adjuvant arthritis (Franch et al., 1990) and there appears to be a positive correlation between urinary NAG excretion and severity of the disease. The present study was undertaken to investigate the excretion of urinary NAG and the pattern of its isoenzymes in different types of rheumatoid arthritis (RA) and compare these values with those in normal healthy subjects. Another objective was to see if there was any correlation between urinary levels of NAG and severity of the disease.

\section{Materials and Methods}

Forty-nine adult patients (mean age 44 years) who were diagnosed to have RA as defined by the criteria of the American Rheumatism Association were included in this study. Out of these, 30 (24 females and 6 males) were found to have seropositive RA, while 19 (15 females and 4 males) were having seronegative RA. Moreover, 15 normal healthy subjects in the same age group were taken as "controls".

Severity of the RA was assessed to be mild, moderate or severe depending upon the number of swollen joints and deformities. Those having involvement of 1-2 joints and no deformities were placed in the mild disease subgroup, while those with involvement of 3-10 joints and deformities of either hands or feet were placed in the moderate disease subgroup. When there were more than 10 swollen joints and deformities of both hands and feet, these patients were placed in the severe disease subgroup. Mean duration of RA in each subgroup was also taken into account. All the RA patients were also assessed to have normal kidney and liver functions. Those patients who had received gold as antirheumatic treatment were not included in this study.

\section{Analysis of NAG}

Morning urine samples were collected from the two groups of arthritis patients as well as from normal healthy subjects. These were dialyzed against $10 \mathrm{mM}$ phosphate buffer, $\mathrm{pH} 7.0$ for $4 \mathrm{~h}$. NAG activity in the dialyzed samples was 
determined by the method of Whiting et al. (1979b). This procedure involves incubation of $0.1 \mathrm{ml}$ of urine diluted with $0.4 \mathrm{ml}$ of distilled water and $4.5 \mathrm{ml}$ of $20 \mathrm{mM}$ citratephosphate buffer, pH 4.4 containing $0.2 \mathrm{mM}$ methylumbelliferyl-glucosaminidine at $37^{\circ} \mathrm{C}$. One $\mathrm{ml}$ from this is then withdrawn at various time intervals $(0 \mathrm{~min}, 5 \mathrm{~min}$, $10 \mathrm{~min}, 15 \mathrm{~min}$ ) and transferred to separate tubes containing $2 \mathrm{ml}$ of $0.5 \mathrm{M}$ glycine- $\mathrm{NaOH}$ buffer, $\mathrm{pH} 10.4$, to stop the reaction.

The fluorescence of 4-methyl umbelliferone (MU) released in each reaction was monitored spectrofluorimetrically at excitation and emission wavelengths of 368 and $448 \mathrm{~nm}$, respectively using JASCO FP-770 spectro-fluorimeter. One unit of NAG activity was defined as that which released 1 mmole of $4 \mathrm{MU}$ per minute under assay conditions. In order to compensate for the production of concentrated or diluted urine samples, NAG activities in urine were expressed as $U$ per gm of urinary creatinine. Urinary creatinine was measured by Boehringer Mann-heim Diagnostics Kit based on Jaffe' method.

\section{Separation of NAG isoenzymes}

Separation of NAG isoenzymes in urine samples was carried out by using a modification of the procedure described by Severni et al. (1988). One $\mathrm{ml}$ of dialyzed urine sample was applied to a minicolumn of DEAESepharose $(1.5 \mathrm{~cm} \times 3.0 \mathrm{~cm})$ which had been equilibrated with $50 \mathrm{mM}$ phosphate buffer, $\mathrm{pH}$ 7.2. The flow rate of the column was adjusted to $15 \mathrm{ml} / \mathrm{h}$. One-ml fractions were collected. First 10 fractions, which contained NAG$B$ isoenzyme, were collected with $50 \mathrm{mM}$ phosphate buffer, $\mathrm{pH}$ 7.2, while NAG-A isoenzyme was eluted using $1 \mathrm{M} \mathrm{NaCl}$. NAG activity in the fractions was determined spectrofluorimetrically as described above.

\section{Statistical analysis}

To compare the distribution of mean values of urinary NAG among various groups under study, one way ANOVA and Tukey-HSD test were used. Comparison of the mean values of two subgroups was also carried out by student- t test.

\section{Results}

Figure 1 shows the mean \pm SD urinary NAG values in the seropositive RA group, seronegative RA group and normal control group. The mean NAG values in these three groups were compared by using one way ANOVA followed by Tukey-HSD test. One way ANOVA indicated that the mean NAG values were significantly different $(P$-value $=0.027, F$ statistics $=3.8377)$. Tukey-HSD test at $5 \%$ significance level further revealed that the mean NAG value in the seropositive RA group was significantly different from the mean NAG values in normal control group and seronegative RA group.

Since one of the objectives of this study was to see if there was any correlation between urinary NAG activity and severity of the disease, RA patients in this study were classified into mild, moderate and severe disease subgroups as described in the Materials and Methods section. Urinary NAG values in these three subgroups have been reported in Tables 1 and 2 .

Comparison of the distribution of NAG values in these subgroups revealed an apparent correlation between mean value of NAG and severity of the disease in seropositive group of RA patients. This was due to the fact that a comparison of the mean NAG values between severe and mild disease subgroups by student-t test yielded a

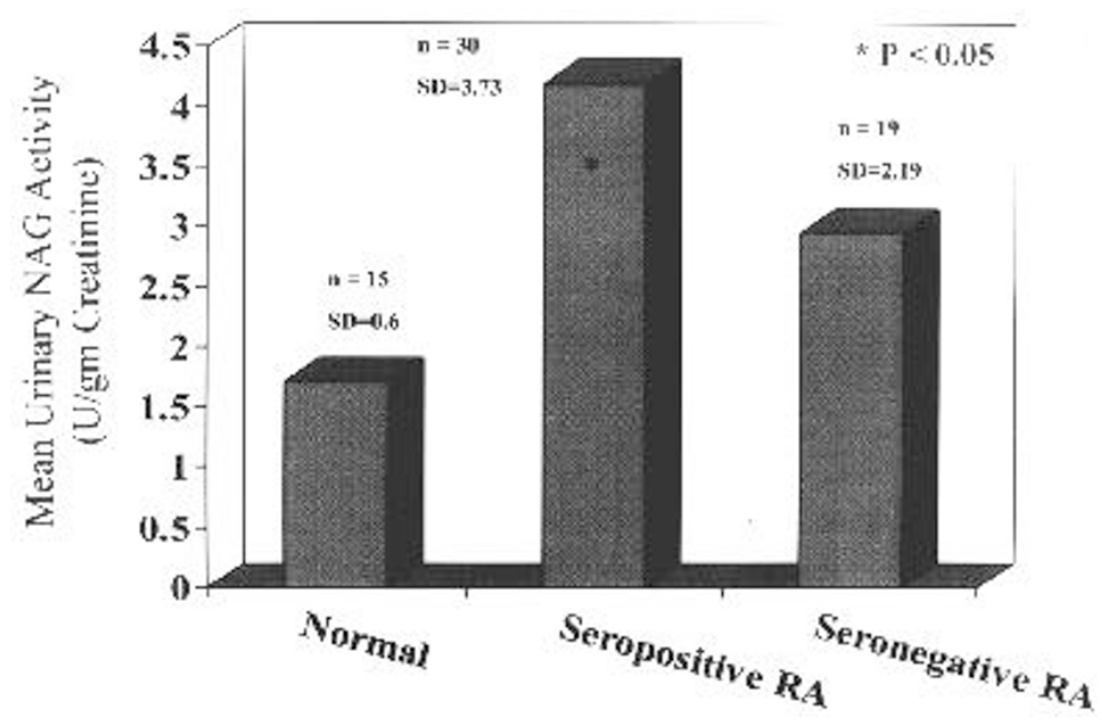

Figure 1. Urinary NAG activity in two groups of rheumatoid arthritis compared to normal control group $(n=$ number of subjects; $S D=$ Standard Deviation). Comparison of the distribution of urinary NAG values in these 3 groups was carried out by using one way ANOVA and Tukey-HSD test. 
Table 1. Comparison of the distribution of urinary NAG values in mild, moderate and severe disease subgroups of seropositive RA. One way ANOVA P-value $=0.21$. Comparison of the mean NAG values between severe and mild disease subgroups by student-t test, however, reveals a significant difference at $P<0.05$.

\begin{tabular}{cccc}
\hline $\begin{array}{c}\text { Disease } \\
\text { Condition }\end{array}$ & $\begin{array}{c}\text { Sample } \\
\text { size }(\mathrm{n})\end{array}$ & $\begin{array}{c}\text { Mean duration } \\
\text { of RA } \pm \mathrm{SD} \\
\text { (years) }\end{array}$ & $\begin{array}{c}\text { Sample Mean } \\
\text { NAG value } \pm \mathrm{SD} \\
\text { (U/g creatinine) }\end{array}$ \\
\hline Mild & 6 & $4.67 \pm 0.47$ & $2.33 \pm 1.20$ \\
Moderate & 12 & $4.87 \pm 3.9$ & $3.82 \pm 3.73$ \\
Severe & 12 & $7.12 \pm 3.45$ & $5.52 \pm 4.25$ \\
\hline
\end{tabular}

Table 2. Comparison of the distribution of urinary NAG values in mild, moderate and severe disease subgroups of seronegative RA. One way ANOVA P-value $=0.803$.

\begin{tabular}{cccc}
\hline $\begin{array}{c}\text { Disease } \\
\text { Condition }\end{array}$ & $\begin{array}{c}\text { Sample } \\
\text { size }(\mathrm{n})\end{array}$ & $\begin{array}{c}\text { Mean duration } \\
\text { of RA } \pm \text { SD } \\
\text { (years) }\end{array}$ & $\begin{array}{c}\text { Sample Mean } \\
\text { NAG value } \pm \mathrm{SD} \\
\text { (U/g creatinine) }\end{array}$ \\
\hline Mild & 13 & $1.7 \pm 1.47$ & $3.16 \pm 2.2$ \\
Moderate & 1 & 0.33 & 3.25 \\
Severe & 5 & $5.89 \pm 7.03$ & $2.57 \pm 2.36$ \\
\hline
\end{tabular}

significant difference at $\mathrm{P}<0.05$ (Table 1). However, when we compared the mean values using more stringent statistical tests, such as one way ANOVA and TukeyHSD test, no significant difference was observed between the mean NAG values in mild, moderate and severe subgroups of seropositive as well as seronegative groups of RA patients (Tables 1 and 2).

Figure 2 shows a typical chromatogram of NAG isoenzymes in the urine samples of a seropositive RA patient, a seronegative RA patient, and a normal healthy subject
Table 3. Comparison of the mean values of the ratio of isoenzyme $B$ to isoenzyme $A$ in two groups of rheumatoid arthritis and a normal control group. One way ANOVA Pvalue $=0.017$. Comparison of the mean values was carried out by using one way ANOVA and Tukey-HSD test.

\begin{tabular}{ccc}
\hline Group & Sample size $(\mathrm{n})$ & $\begin{array}{c}\text { Mean } \pm \text { SD } \\
\text { isoenzyme B/isoenzyme A }\end{array}$ \\
\hline Normal & 7 & $0.407 \pm 0.22$ \\
Seronegative RA & 9 & $0.795 \pm 0.38$ \\
Seropositive RA & 15 & $1.284 \pm 0.85$ \\
\hline
\end{tabular}

eluted from a DEAE-Sepharose column. All the three samples resolved into NAG-B and NAG-A isoenzymes. The mean values of the proportion of NAG-B to NAG-A in the urine samples of three groups of subjects in this study have been shown in Table 3. One way ANOVA showed the mean proportion values of NAG-B/NAG-A to be significantly different among three groups ( $P$-value $=0.017, \mathrm{~F}$ statistics $=4.74)$. Tukey-HSD test further indicated that the mean value of NAG-B / NAG-A obtained in seropositive RA patients was statistically different from the mean values obtained in normal healthy subjects and in seronegative RA patients at $5 \%$ significance level. This suggests that the increase in total urinary NAG, at least in seropositive RA patients, is contributed mainly by NAG$B$ isoenzyme.

\section{Discussion}

This study shows that total activity of NAG in urine is significantly elevated in seropositive RA patients compared to normal healthy subjects. Urinary NAG is known to be a sensitive indicator of kidney injury as its levels increase before other renal function tests (especially

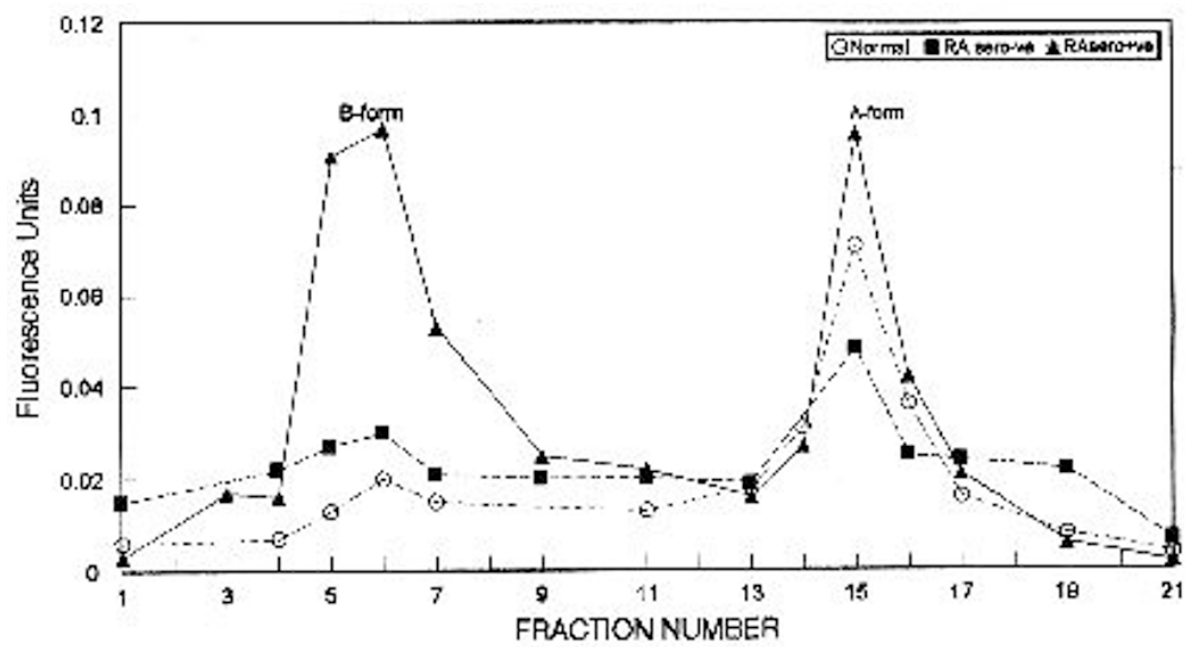

Figure 2. A typical chromatogram of NAG isoenzymes (NAG-A and NAG-B) in urine of a normal healthy subject and two patients suffering rheumatoid arthritis after elution from a DEAE-Sepharose column. Experimental conditions have been provided in the 'Materials and Methods' section. 
serum crea-tinine) become abnormal (Price, 1982). Therefore, increased excretion of NAG may reflect renal damage in RA. This is further supported by the observation that the apparent value of urinary NAG in most cases of severe seropositive RA appeared to be on the higher side compared to the mild cases of this disease. A similar correlation has pre-viously been reported between urinary NAG and degree of nephropathy in diabetic patients (Whiting et al., 1979a; Shimajo et al., 1987; Skrha et al., 1987; Jung et al., 1988; Watts et al., 1988), however, no clear correlation to degree of retinopathy was established in these patients with complications of diabetes mellitus (Agardh et al., 1987, 1991; Watts et al., 1988). This shows that any disease having a direct or indirect effect on kidney tubular function would be expected to be associated with increased levels of NAG in the urine. Franch et al., (1990) have also reported a positive association between urinary NAG excretion and disease severity in adjuvant arthritis.

In an earlier communication we have reported increased levels of serum NAG in different arthopathies including RA (Iqbal et al., 1998). However, it is unlikely that the increased level of NAG in urine is contributed by the increased level of this enzyme in serum as the molecular size of the enzyme is high enough to prevent its passage through the glomerulus. Thus, the origin of urinary NAG appears to be the kidney tubules. Since we measured the values of NAG as units/gm of creatinine, any change occurring in the clearance of creatinine as a result of concomitant use of drugs affecting glomerular filtration rate, such as, non-steroidal anti-inflammatory drugs (NSAIDs) etc. are not likely to interfere with our results.

Isoenzymes of NAG (NAG-B and NAG-A) in urine have been reported to be of value in assessing complications of diabetes mellitus (Severini et al., 1988; Agardh et al., 1991). It has been shown that only low amounts of NAG$B$ are present in normal urine, however, the activity of this isoenzyme significantly increases in most cases of diabetes mellitus (Severini et al., 1988). Our results also show that the ratio of NAG-B to NAG-A significantly increases in severe cases of seropositive RA.

Renal damage is not uncommon in $R A$, but the causative role of the disease per se has not been defined as yet (Manganaro et al., 1994). Yoshida et al. (1991) have reported two cases of native nephropathy in RA. Our data also suggest that subclinical renal injury without compromising renal function is a possibility in RA especially in severe cases of this disease. It is unclear which factors lead to increased excretion of NAG (especially the isoenzyme form B) in RA patients. The role of (NSAIDs) and certain disease modifying antirheumatic drugs, such as, gold in producing nephropathy cannot be discounted (Yoshida et at., 1991. Kordonouri et al., 1994). Keeping that in view, we have not included in this study those patients who had received gold therapy. According to the study by Kordonouri et al., (1994) subclinical renal injury due to therapeutic doses of NSAIDs is more likely to affect the glomerular function rather than the tubular function. Hence, NAG, which is an enzyme marker for the tubular function, is not expected to increase in urine due to therapeutic doses of NSAIDs. In a more recent study, Wiland et al. (1997) have reported NAG to be a more sensitive indicator of kidney dysfunction in RA than microalbuminuria. They also showed that methotrexate in low dosages does not cause any marked damage to renal proximal tubules.

All these reports lend further support to the notion that subclinical damage to kidney may occur in RA. Determination of serum creatinine which is a routine procedure for assessing kidney function is unlikely to detect those changes as increased concentration of creatinine in serum is not observed until over half of the glomerular function is compromised (Lente and Suite, 1989). Determination of urinary NAG along with excretion of creatinine may, therefore, serve as a more sensitive test for kidney injury in RA and measurement of the levels of its isoenzymes could be of value in providing additional diagnostic information regarding the status of this disease.

\section{Acknowledgements}

We gratefully acknowledge the help provided by Dr. M. Azmat Hussain and Dr. Iqbal Ahmed in procuring some of the clinical samples. We are also thankful to Dr. Saadia Mahmood for her help in statistical analysis of the data.

\section{References}

Agardh, C.-D., Agardh, E., Isaksson, A. and Hultberg, B. (1991) Association between urinary - $\beta$-D-glucosaminidase and its isoenzyme patterns microangiopathy in Type 1 diabetes mellitus. Clin. Chem. 37: 1696-1699

Agardh, C.-D., Agardh, E. and Hultberg, B. (1987) Lack of relationship between $\beta$ hexosaminidase activity and retinopathy in insulin dependent diabetics. Clin. Chim. Acta 167: $37-42$

Ellis, B. G., Tucker, S. M., Thompson, A. E. and Price, R. G. (1975) Presence of serum and tissue forms of $N$-Acetyl- $\beta$-D-glucosaminidase in urine from patients with renal disease, Clin. Chim. Acta 64: 195-202

Franch, M. A., Moreno, J. J., Castell, M. and Queralt, J. (1990) Urinary N-Acetyl- $\beta$-Dglucosaminidase as marker of renal injury in adjuvant arthritis. Res. Exp. Med. Berl. 190: $213-218$

Hanseus, K., Hultberg, B., Isaksson, A. and Sjoblad, S. (1983) Plasma and urinary $\beta$ hexosaminidase in juvenile diabetes mellitus. Acta Pediatr. Scand. 72: 77-80

Iqbal, M. P., Ali, A. A., Hussain, M. A, Mehboobali, N., Waqar, M. A., Javed, M. H. and Rahbar, M. H. (1998) Role of $N$-acetyl- Acetyl- $\beta$-D-glucosamini-dase in the diagnosis of arthopathies. Clin. Chem. Enzym. Comms. (in press)

Javed, M. H., Hussain, A. N. and Waqar, M. A. (1992). Estimation and separation of NAcetyl- $\beta$-D-glucosaminidase isoenzymes in urine. J. Pak. Med. Assoc. 42: 64-66

Jung, K., Pergande, M., Schimke, E., Ratzmann, K. P. and llius, A. (1988) Urinary 
enzymes and low-molecular-mass proteins as indicators of diabetic nephropathy. Clin. Chem. 34: 544-547

Kordonouri, O., Dracou, C., Papadellis, F., Touroutsika, P., Muller, C. and Jorres, A. (1994) Glomerular microproteinuria in children treated with nonsteroidal antiinflammatory drugs for juvenile chronic arthritis. Clin. Exp. Rheumatol. 12: 567-571

Lente, V. F. and Suite, P. (1989) Assessment of renal function by serum creatinine and creatinine clearance: Glomerular filtration rate estimated by four procedures. Clin. Chem. 35: 2326-2330

Manganaro, M., Bruno, M., Ravarino, N., Pellerito, R., Cosseddu, D., Torchio, B., Urbano, D. and Linari, F. (1994) Renal damage in rheumatoid arthritis. Minerva. Urol. Nefrol. 46: $55-60$

Price, R. G. (1982) Urinary enzymes, nephrotoxicity and renal disease. Toxicology 23 $99-134$

Severini, G., Alberti, L. M., Di Girolamo, M. (1988) N-Acetyl- $\beta$-D-gluco-saminidase isoenzymes in serum and urine of patients with diabetes mellitus. Clin. Chem. 34: 24302432

Shimajo, N., Kitahashi, S., Naka, K., et al. (1987) Comparison of N-acetyl- $\beta$-Dglucosaminidase and alanine aminopeptidase activities for evaluation of microangiopathy in diabetes mellitus. Metabolism 36: 277-280
Skrha, J., Perusicova, J., Stolba, P., Stibor, V. and Pav, J. (1987) Comparison of $N$-acetl- $\beta$ $\mathrm{D}$-glucosaminidase and albuminuria with clinical finding of microangiopathy in type I diabetes mellitus. Clin. Chim. Acta 166: 135-141

Watts, G. F., Vlitos, M. A. J., Morris, R. W. and Price R. G. (1988). Urinary N-Acetyl- $\beta$-Dglucosaminidase excretion in insulin-dependent diabetes mellitus: relation to microalbuminuria, retinopathy and glycemic control. Diabetes Metab. 14: 653-8

Whiting, P. H., Ross, I. S. and Borthwick, L. J. (1979a). N-Acetyl- $\beta$-D-glucosaminidase levels and diabetic microngiopathy. Clin. Chim. Acta 97: 191-195

Whiting, P. H., Ross, L. S. Borthwick, L. J. (1979b) N-Acetyl- $\beta$-D-gluco-saminidase in diabetics on diagnosis and subsequent treatment, and stable insulin dependent diabetics. Clin. Chim. Acta 97: 459-463

Wiland, P., Swierkot, J. and Szechinski, J. (1997) N-Acetyl- $\beta$-D-gluco-saminidase in rheumatoid arthritis patients on low-dose methotrexate treatment. Br. J. Rheumatol. 36: $59-63$

Yoshida, A., Morozumi, K., Suganuma, T., Aoki, J., Sugito, K., Koyama, K., Oikawa, T., Fujinimi, T. and Matsumoto, Y. (1991) Clinicopathological study of nephropathy in patients with rheumatoid arthritis. Ryumachi. 31: 11-21 